\title{
ESQUIZOFRENIA E PSICOSES DEGENERATIVAS DE KLEIST: PATOGENIA E PSICOPATOLOGIA DIFERENCIAIS
}

\author{
ANíbal Silveira *
}

Ao substituir a expressão demência precoce pelo têrmo esquizofrenia, Bleuler não sòmente redefiniu os quadros clínicos de Kraepelin mas lhes ampliou ao mesmo tempo o conceito doutrinärio. Tal operação, ditada em essência pela concepção dinâmica da Psiquiatria, foi saudada com entusiasmo pelos psiquiatras, principalmente porque ajustava o conceito diagnóstico à evolução clínica de numerosos pacientes incluidos na categoria da demência precoce. Ademais, como acentua Minkowski ${ }^{20}$, o conceito afastava o pessimismo doutrinário e abria perspectivas terapêtuticas. Mais ponderável, a nosso ver, como fator de aceitação, era porém o comodismo lógico. O fato de não pressupor demência tornou mais fácil estender êsse diagnóstico a casos clínicos que antes exigiriam reflexão e suscitariam escrúpulos.

Aquilo que representou verdadeiro progresso na atitude médica logo se tornou empecilho para o aperfeiçoamento diagnóstico. Basta recordar a frouxidão de conceito revelada por Schneider ${ }^{27}$ no seguinte passo: "Onde existe delírio na acepção legítima, existe assim sintomatologia esquizofrênica; e portanto, se não se apura nenhuma causa etiológica, existe clinicamente esquizofrenia". "Dizemos: quando psicoses de etiologia obscura assumem os mencionados traços, chamamo-las esquizofrênicas" (pág. 329, grifos do original). E isto na Alemanha de quando já estava em vigor a "Lei de combate à difusão de doenças hereditárias", onde se impunha esterilização em face de uma lista de estados mórbidos na qual a esquizofrenia representava o segundo item. Mesmo sem levar em conta essa aberração nazista sancionada em julho de 1933, pelo aspecto de prática clínica tal imprecisão de conceito se tornou prejudicial. A esquizofrenia entrou a absorver a quase totalidade dos diagnósticos, para a grande maioria dos psiquiatras. E dessa maneira, compatível com todos os tipos de decurso, com tôdas as modalidades de aparecimento, com qualquer cabedal heredológico do paciente, com a mais variada sintomatologia mental, perdeu por completo o valor prognóstico, além de estimular o descaso para com a pesquisa clinica. Por isso não se fêz esperar a reação contra a utilização do diagnóstico de esquizofrenia simplesmente. Para todo especialista criterioso o conhecido tripé diagnóstico de Bleuler passou a ser

Trabalho inscrito no I Congresso Peruano de Neuro-Psiquiatria (Lima, novembro de 1958).

* Docente Livre de Psiquiatria da Fac. Med. da Univ. de São Paulo; Professor de Psicopatologia da Fac. Filosofia, Ciências e Letras da Univ. de São Paulo. 
insuficiente, bem como a expressão esquizofrenia pura e simples. Daí as dissenções teóricas e o retôrno à valorização dos dados clínicos objetivos. Mira y Lopez ${ }^{21}$, por exemplo, encarece a "necessidade de buscar o maior número possivel de sintomas primários e não assentar jamais afirmaçōes dogmáticas, baseadas na comprovação de dois ou três sintomas esquizofrênicos isolados sem tomar em consideração o aspecto de conjunto da evolução psicótica: os antecedentes hereditários, o tipo corporal, a caracteriologia pré-psicótica, as possíveis causas psíquicas, a fenomenologia mórbida inicial, hāo de completar os dados do status praesens e integrar-se harmônicamente, antes de pronunciar-se o diagnóstico; o qual, de outra parte, se bem fundamentado, sempre permitirá dizer algo mais que a palavra esquizofrenia" (pág. 554, grifos do original).

Mais do que qualquer outra ocorrência clínica, a esquizofrenia exige diagnóstico diferencial. E tal cuidado se impõe não só em função dos diversos métodos terapêuticos (Neele ${ }^{23 a}$, Silveira $32 \mathrm{~b}, \mathrm{~d}, \mathrm{f}$ ) como principalmente pelo que tal eventualidade implica para a corrente genética, segundo acentuam Faust ${ }^{4}$, Kleist e Wissmann ${ }^{16}$, Leonhard ${ }^{18 \mathrm{~b}, \mathrm{~m}}$ e como nós mesmo tivemos ocasião de discutir $32 h, j$. Em realidade o problema conceptual da esquizofrenia nāo consiste em encontrar definiçōes que adaptem o diagnóstico à multiplicidade de decursos clínicos e portanto se aplique a qualquer caso. Essa foi a solução encontrada por Bleuler ao rejeitar a denominação demência precoce. Ao contrário, tal problema reside em depurar o critério diagnóstico de modo a não se confundir a entidade mórbida em causa com outros quadros que com ela se pareçam apenas pelo aspecto fenomenológico. Para isto é indispensável que o diagnóstico se apoie na psicopatologia e na patogênese dos sintomas mórbidos, em sentido diferencial. Semelhante alvo só foi plenamente atingido, em nosso entender, por Kleist e pela escola de Frankfurt am Main.

\section{ESQUIZOFRENIA, SEGUNDO KLEIST E ESCOLA}

Tomando rumo diverso do de Kraepelin, que procurou reunir em um único grupo a hebefrenia, a catatonia e as demências primárias, Kleist procurou separar no âmbito de cada uma delas o quadro pròpriamente endógeno e os quadros afins meramente sintomáticos que com êle se confundiam. Pôde então estabelecer critério nosológico rigoroso e distinguir, dentro da entidade descrita por Hecker, o que era hebefrenia e o que eram quadros sintomáticos aparentemente hebefrênicos; dentro da entidade mórbida de Kahlbaum, o que deveria conservar o diagnóstico de catatonia e o que deveria ser afastado como simulacro clínico de catatonia. Igualmente, entre as formas mentais delirantes, descreveu as que ofereciam decurso progressivo, como transtôrno endógeno de tipo demencial sa, e as outras análogas, transitórias ou mesmo de origem meramente ocasional. Cinco anos mais tarde reuniu no grupo de "embotamentos endógenos" as várias condiçōes patológicas que levavam ao estado demencial, quer primàriamente ligadas à elaboração delirante, quer consistentes de inicio em desordens afetivas ou 
em desordens motoras ${ }^{9 e}$. Já por essa época demonstrara, por essa forma, não sỏmente que deviam manter-se como autônomas a catatonia e a hebefrenia - devidamente depuradas - mas também que era necessário estabelecer a mesma distinção no domínio das formas restantes da esquizofrenia, mesmo quando consideradas doenças progressivas, constitucionais, desvencilhadas das doenças sintomáticas.

Note-se a diferença essencial entre a concepção de Kleist e a diretriz tomada por Kraepelin e depois por Bleuler. O crivo da patogênese permitiu como que separar o joio e o trigo, ao passo que as tendências para a sintese e para a simplificação levaram a agravar o êrro originário, a partir de material já heterogêneo. O material de Erlangen e principalmente o de Rostock levaram Kleist a restringir o diagnóstico de esquizofrenia em sentido próprio ao "embotamento incoerente" e a considerar mais seis formas acessórias, entre as quais a esquizofasia. Tornara-se o grupo mais numeroso das formas mórbidas progressivas, pais que na catatonia divisava quatro modalidades, e três na hebefrenia (quadro 1). Ao estudar a patogenia dos sintomas na esquizofasia ressaltou que algumas vêzes os pacientes se distinguiam pela "incoerência do fluxo ideativo e pelas paralogias". A sistematização destas pesquisas deu origem, mediante revisão catamnéstica, ao desmembramento das formas confusionais entre as do grupo paranóide. Ao mesmo tempo a noção de sistemas cerebrais - que permitia distinguir desordens da linguagem e desordens intrínsecas do pensamento - constituiu o fundamento da concepçāo da esquizofrenia $9 g$. Os vários sistemas que explicam as diversas expressões clínicas da esquizofrenia são, no caso, atingidos por déficit biológico ${ }^{9 k}$. Os distúrbios do pensamento de ordem paralógica ou de tipo primário, alógico ${ }^{91}$, representam sintoma distintivo na esquizofrenia.

A segurança com que foram estabelecidas as diversas formas esquizofrênicas no material clínico de Erlangen e de Rostock foi posta em evidéncia pelo notável estudo de Leonhard is $c$ relativo a esquizofrènicos em fase residual. Trabalhando com pacientes de ambos os sexos e de vária procedência, chegou Leonhard às mesmas subdivisões que Kleist, salvo pequenas modificaçōes em parte devidas ao estádio mórbłdo, em parte como expressão de diferenças que apenas a fase crônica permitiria evidenciar. A êsse respeito diz êste autor, ao comparar ambas as sistemáticas: "Na denominação teria sido possivel em parte uma nova assimilação, porém eu quis que em geral transparecessem também na designação das formas os sintomas mais marcantes, uma vez que estabeleci inicialmente em sentido puramente descritivo os quadros clínicos em estado residual. A indicação "progressiva" na acepção de Kleist já não poderia empregar, dado que tinha diante de mim somente estados terminais nāo mais em progressão" (pág. 111)

As formas atipicas pela fisionomia clinica encontraram no estudo de Leonhard a explicaçāo genética. Ao passo que na maioria dos casos, em cêrca de 440 , foi possivel classificar sem hesitação em uma das subformas descritas, em 90 não se verificou tal facilidade. Pesquisando os antecedentes genealógicos em ambos os grupos, sentiu logo a necessidade de tornar mais exigente e aprofundada a investigação heredológica. Restringindo o material àqueles pacientes cujos parentes haviam sido internados, a fim de ter em mãos a respectiva descricão médica, e pondo de parte os protocolos em que a psicose em causa fora de orlgem lesional, obteve para estudo 55 esquizofrênicos-indice. Dêstes, 33 eram de forma atipica, enquanto que no total de casos esta assumia apenas a proporção de 1:5. Quase sem exceção, as formas esquizofrênicas neste rol de parentes eram também atipicas. "Essas for- 
mas atípicas pertencem a um grupo de doenças esquizofrênicas que pode ser separado do das esquizofrenias residuais típicas näo somente pelo quadro clínico senão também pelo decurso periódico com entrada, muita vez tardia, para o estágio residual - nem sempre muito acentuado - e por uma forma peculiar de hereditariedade" ${ }^{16}$ d (pág. 131).

A concepção de que nas formas típicas estão em jôgo sistemas cerebrais definidos encontrou apoio em outras pesquisas genealógicas e catamnésticas da escola de Kleist: algumas formas se evidenciaram do mesmo passo complexas quanto à sintomatologia e constantes através da progressão para a fase crônica. Dai considerarem-se como devidas à combinação de sistemas no processo mórbido e portanto como formas combinadas. A importância fundamental dessa concepção de sistemas cerebrais, já comprovada nos quadros lesionais, assim chamados orgânicos ${ }^{32 a}$, fôra em parte ressaltada no material clinico de ferimentos cerebrais de guerra. Porém, como o reconhece Kleist, sòmente as psicoses endógenas, com as finas dissociaçōes do dinamismo cerebral a poderiam pôr em plena evidência. $E$ entre estas figuram, em primeiro plano, a êsse respeito, as modalidades esquizofrênicas. Por outro lado, esta base fisiopatológica cerebral é que confere ao estudo das doenças mentais, mesmo as de tipo funcional ou dinâmico, a precisão e a limpidez de raciocinio das quais até então só o neurologista dispunha. Por isso julgamos necessárias algumas indicações a respeito.

Kleist divide o manto cortical em 9 esferas, cada uma das quais abrange vários campos arquitetônicos. Na convexidade do hemisfério (fig. 1) situa 5 delas, assim distribuidas: a visual, compreende as áreas de 17 a 19 , como é clássico; a esfera auditiva corresponde a região temporal (campos de 20 a 22, 37, 38, 41, 42, 52); a táctil (áreas de 1 a 3, 5, 7, 19 e 40) também se estende para a região pré-central, campos 4 e $6 a \alpha$; a gustativa se reduz ao campo subcentral 43 ; finalmente, a proprioceptiva ou labirintico-miostética é formada pelas áreas $6 \mathrm{a} \beta, 8$ a 10,44 a 46 . $\mathrm{Na}$ figura 2 aparecem as esferas da face inter-hemisférica com as regiōes que lhe são peculiares, de VI a IX, em cuja concepção Kleist revela notável originalidade, para o que se apoia na experimentação e na clínica. As áreas do lobo orbitário e do cíngulo (11 Fg e FH, 23, 24, de 29 a 32) compõem a esfera cenestésica; as regiões VIII e IX, esfera olfativa, englobam os campos Fd, CA, 25, 27, 28 e de 33 a 35 situados nos lobos piriforme e amônico. Em tôdas essas esferas os campos se dividem, segundo Kleist, em tipos funcionais motor, sensorial, psiquico, ou mistos (sensóriomotor, psico-sensorial).

No original ${ }^{\text {in }}$ tais atribuiçōes funcionais sāo assinaladas por pontilhados dtversos. Na versão das figuras 1 e 2 utilizamos em lugar dos pontilhados as iniciais correspondentes ao destino funcional. Além disso, modificamos a interpretação funcional de alguns campos das regiones parietal e frontal, para o que, entretanto, nos baseamos na descrição que Kleist apresentara em relação a essas áreas na Gehirnpathologie, onde vēm as mesmas cartas funcionais (figuras 427 e 428 dessa obra). Em nossa apresentação figuram assim as iniciais p-m, função psicomotora, e p-s-m, psico-sensorial-motora. E o caso do campo $6 a \alpha$, na região III, esfera táctíl, para o qual Kleist admite o tipo sensório-motor mas ao qual atribui sensação de fôrça e participação em "funçôes motoras mormente as de ordem mais elevada" como destrezas, inclusive formação de tons e de sons: dal a nossa indicação p-s-m. Na região frontal, esfera $V$, mudamos para $p-s$ e $p-m$, respectivamente, a designação dos campos 8 e 44a, sensório-motores no original. Ambos participam de atividades psiquicas, tais a direção dos olhos, a linguagem articulada, a construcão de melodias; também com referência ao campo $6 \mathrm{a} \beta$, as atividades psiquicas reclamam inclusão da inicial $p$ como indicio de função mista. 


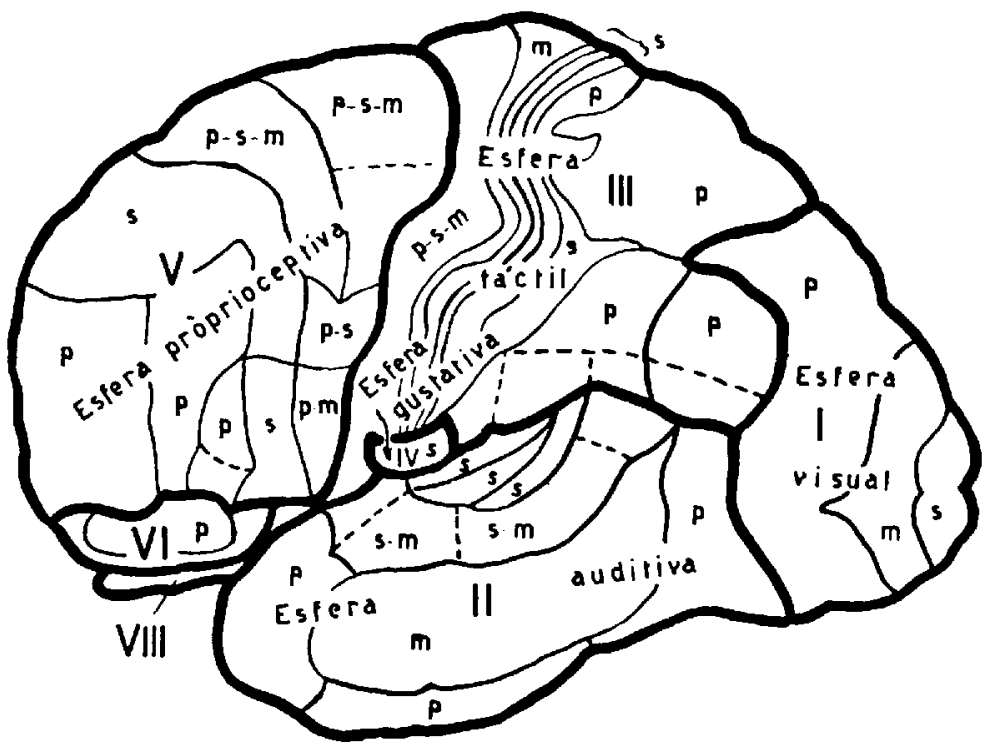

Fig. 1 - Esferas e zonas corticais, segundo Kleist ${ }^{9 m}$ (convexidade do hemisfério esquerdo). Acrescentamos a designacăo das esferas $e$ substitúmos por iniciais o assinalamento das zonas.

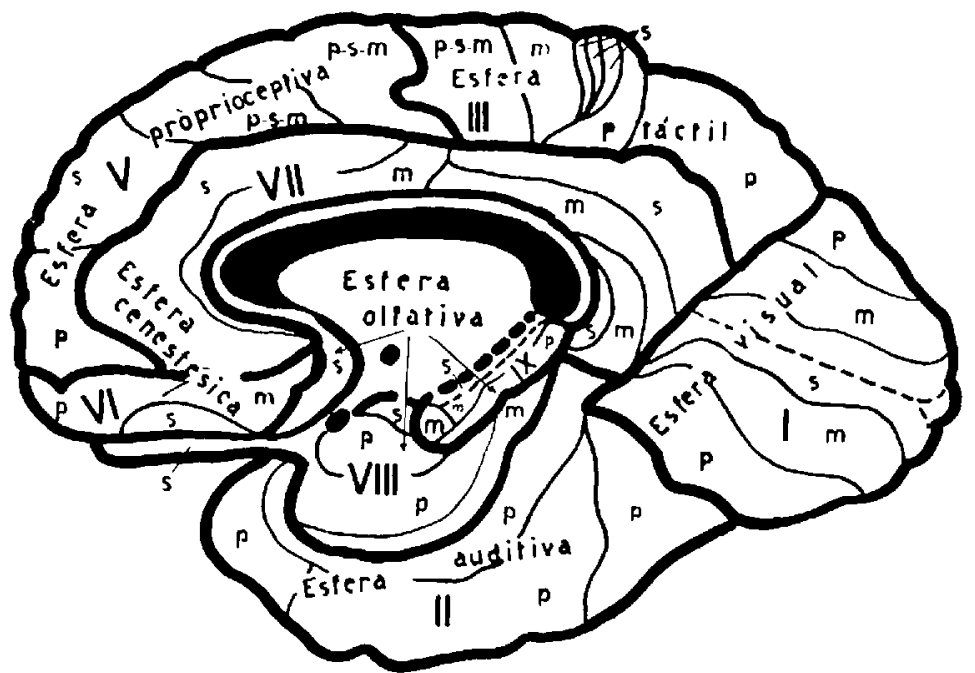

Fig. 2 - Esferas e zonas corticais, segundo Kleist ${ }^{g i n}$ (hemisfério direito, face inter-hemisférica). Como na figura 1, as áreas arquitetônicas numeradas no original — são as de Brodmann. Zonas: m, motora; $p$, psiquica; $s$, sensarial; $p-m ; p-s, p-s-m$ e $s-m$, mistas. 
Por outra parte entendemos esferas da personalidade em sentido algo diverso do de Kleist: no de setores gerais, tais o da afetividade, o da atividade ou conação e o da inteligència. E os sistemas cerebrais não correspondem, na acepção que adotamos, a conjuntos de áreas cerebrais equivalentes em função, mas a conjuntos em que alguns componentes regem aos outros, de modo a haver entre êles hierarquia funcional. Não vem ao caso analisar aqui êsse aspecto da dinâmica cerebral, pelo qual temos norteado outros trabalhos ${ }^{32} \mathrm{~b}, \mathrm{c}, \mathrm{c}, \mathfrak{l}$. Mas na prática as deduçóes clínicas a que chega Kleist não divergem das que são peculiares à escola que seguimos.

A utilização do critério patogenético, orientado pela concepção da patologia cerebral de Kleist e pelas investigaçōes heredológicas diferenciadas, deu em resultado primeiramente a subdivisão das formas esquizofrênicas como entidades clínicas autônomas (quadro 1). Permitiu em seguida, graças à revisão catamnéstica sistematizada, distinguir quadros uniformes durante tôda a evolução e quadros variáveis seja em função da heterogeneidade dos dinamismos cerebrais seja devido ao modo de decurso. Houve, dessa maneira, possibilidade de estabelecer quadros esquizofrênicos tipicos e outros atípicos. No primeiro caso a estabilidade das manifestações mórbidas se devia ao fato de estarem os distúrbios circunscritos a um único sistema cerebral. No segundo surgiram as formas em que dois sistemas ou mais eram atingidos de modo comparável, o que resultava em feitio clínico complexo, porém compreensivel, o das formas combinadas; ou ainda aquelas em que o prccesso mórbido se ampliava, com a extensão sucessiva a outros sistemas

KLEIST (fase progressiva)

LEONHARD (fase residual)

Embotamento incoerente (esquizofrenia em sentido estrito)

Fantasiofrenia

Alucinose progressiva

Psicose progressiva de referência Somatopsicose progressiva

Autopsicose progressiva

Esquizofasia

Catatonia hipocinética

Catatonia paracinética

Catatonia negativista

Catatonia esteriotipico-iterativa

Hebefrenia pueril

Hebefrenia depressiva

Hebrefenia improdutiva
Esquizofrenia residual incoerente

Fantasiofrenia

Alucinose verbal residual

Alucinose hipocondriaca residual

Esquizofrenia paranóide expansiva residual

Esquizofrenia residual autistica

Esquizofasia

Catatonia residual mutista

Catatonia residual rigida

Catatonia residual loquaz

Catatonia residual afetada

Catatonia residual negativista

Catatonia residual prosética

Hebefrenia residual taciturna?

Hebefrenia residual pueril

Hebefrenia residual taciturna

Quadro 1 - Formas de esquizofrenia segundo Kleist e segundo Leonhard. Confronto de Leonhard ${ }^{18 d}$ o primeiro item desta tradução é o sexto do original (pág. 111). 
cerebrais. Entretanto, a discriminação da patogênese, apurada no estudo catamnéstico, veio mostrar que tanto as formas simples como as combinadas ofereciam a possibilidade de se reconhecerem os sistemas cerebrais em causa, o que não se passava com as formas extensivas. Sob o aspecto da patogênese, pois, os dois primeiros grupos se afirmam como sistemáticos. Esta última separação entre formas clínicas prevaleceu nos estudos mais recentes (Kleist 9p, r, Leonhard ${ }^{18 n, p}$, Schulte-von der Stein ${ }^{29}$ ).

Postas em confronto essas duas maneiras de considerar os quadros clínicos, temos (quadro 2):

\begin{tabular}{|c|c|c|c|}
\hline Configuracão: & Típicas & \multicolumn{2}{|c|}{ Atipicas } \\
\hline Quadros clinicos: & Formas simples & Formas combinadas & Extensivas \\
\hline Patogenia: & & icas & Assistemát \\
\hline
\end{tabular}

Quadro 2 - Configuraç̄o e patogenia das formas esquizofrênicas.

Paralelamente a essa verificacão doutrinária, o aprofundamento da investigação clinico-3rcalizatória, já iniciada por Leonhard no material clinico crônico sad, foi intensificado pelos discipulos e colaboradores de Kleist. O núcleo inicial de doenças progressivas por alterasōes de sistemas se viu então ampliado apenas com o prosseguimento da reavaliaçāo patogênica feita pelo insigne mestre de Frankfurt am Main. Já lembramos que êste divisara no âmbito das doenças paranóides aquelas em que o quadro confusional se fazia conspicuo: confusão devido às alteraçôes intrinsecas da iinguagem - esquizofasia - e confusão pelo transtörno do raciocínio, em razão de simplificações, de desvios e de transposiçōes na formação dos conceitos (formas paralógicas). Dai resultou o isolamento das formas confusionais, no âmbito do grupo esquizofrênico em que a patogènese predomina no campo intelectual. A partir do conceito inicial da dinâmica do pensamento em plano mórbido ${ }^{91}$, a revisão do material após jongo decurso revelou as formas esquizofásicas ${ }^{2 \pi}$, também estudadas entre nós por vizzotto e Melsohn ${ }^{39}$ e as modalidades primàriamente confusionais (Kleist e Schwab ${ }^{15}$, Leonhard ${ }^{181, k}$, Schwab ${ }^{30}$ e, Tomchinsky ${ }^{37}$ ). O grupo confuso-esquizofásico passou a compreender quatro formas tipicas e mais uma variedade atípica - a esquizofrenia confusional por surtos - em lugar da única modalidade admitida de inicio.

Nos demais grupos das formas paranóides igual ampliasāo se verificou. O desmembramento encetado por Kleist $9 \mathrm{~g}$ e levado a cabo com a pléiade de colaboradores estabeleceu com precisão os diferentes quadros de natureza delirante ${ }^{90, q}$; contribuiram para isso mais diretamente Faust ${ }^{3}$, Meyer ${ }^{19}$, Neele ${ }^{24}$, Schneider ${ }^{25}$, Schwab ${ }^{30} \mathrm{~b}$ e especialmente Leonhard. Este pesquisador trouxe relevantes ensinamentos de ordem patogênica e heredobiológica $1 \mathrm{f} f \mathrm{a} l$, evidenciando ainda as formas atípicas, a variedade ansioso-extática, as formas fantásticas periódicas, discriminando as formas paranóides periódicas e isolando a parafrenia afetiva. Com tais desdobramentos o grupo paranōide se compōe de seis formas tipicas sistemáticas e três assistemáticas: eram seis as modalidades do inicio, näo computada ai a esquizofasia (quadro 1).

Igual escrutínio no âmbito da catatonia e da hebefrenia produziu muito menor ampliação, como é fácil compreender: patogênicamente os distúrbios são aí mais caracteristicos para a configuração clinica e assim Kleist pudera precisá-los logo no material inicial. As formas catatônicas passaram ao dôbro e o campo da hebefrenia só se acresceu de uma forma. Trabalhos do próprio Kleist ${ }^{9}{ }^{9}$,n e dos colaboradores Herz ${ }^{11}$, Leonhard ${ }^{18} \mathrm{~g}, \mathrm{~h}$, Pittrich e $\operatorname{Schwab}^{18},{ }^{14},{ }^{30 \mathrm{a}}$, quanto à catatonia, Faust 
quanto à hebefrenia ${ }^{12}$, ultimaram a estruturação do conjunto de doenças esquizofrênicas, inclusive formas assistemáticas. Estas últimas só não se apreciam no domínio da hebefrenia, o que ainda uma vez revela a estabilidade do dinamismo patogênico aqui em ação. Mostra-o o quadro 3, tal como se estabeleceu nas últimas classificaçōes de Kleist e de Schulte-von der Stein, em $1947^{\circ}$ p, em $1953^{\circ} \mathrm{r}$ e em $1955^{29}$. A validade clínica e heredológica dêsse vasto grupo mórbido tem sido amplamente confirmada: Edelmann ${ }^{2}$ e Fish ${ }^{5}$ comprovaram tôdas as subdivisōes de Kleist e Leonhard, bem como Knauf ${ }^{17}$ e Schneider ${ }^{26}$ o fizeram em hospital para crônicos e Schulte-von der Stein ${ }^{29}$ em secçāo feminina de crônicos.

\section{PSICOSES ENDOGENAS DEGENERATIVAS}

Ao lado da sistematização das pesquisas sôbre a esquizofrenia deve a Psiquiatria imensos progressos a Kleist no âmbito de outras psicoses, também endógenas mas de dinamismo patogênico diverso. Tais são as formas mórbidas por êle arroladas como endógenas e autóctones porém com o cognome de benignas e atipicas: benignas pelo decurso - análogo a êste respeito ao da psicose maníaco-depressiva - caracterizado pela remissão integral sem déficit mental; atípicas pelo fato de assumirem configuraçōes clínicas que as faz confundir com quadros endógenos constitucionais e entretanto decorrerem de modo inteiramente diverso, com restituição ao estado integral de normalidade.

\begin{tabular}{l|c|c}
\hline $\begin{array}{l}\text { Formas sistemáticas } \\
\text { Simples }\end{array}$ & Combinadas & $\begin{array}{c}\text { Formas assistematicas } \\
\text { Extensivas }\end{array}$ \\
\hline & $\mid$ Formas afetivas: hebefrenias
\end{tabular}

Pueril; Depressiva; Apática; Au-
tista.
Formas psicomotoras: catatonias
Negativista; Procinetica; Acinéti-
ca; Esteriotipica; Paracinética;
Mutista; Loquaz.
Formas delirantes: paranóides

Autopsicose progressiva Somatopsicose progressiva Alucinose progressiva Confabulose progressiva Psicose progressiva de influência Psicose progressiva de insplração

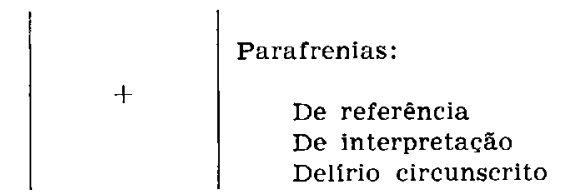

Fornas confusionais

Esquizofrenia incoerente Esquizofrenia paralógica Fantasiofrenia Esquizofasia

Esquizofrenia confusional, por surtos

Quadro 3 - Formas esquizofrênicas, segundo Kleist. Revisôes publicadas em 1947.p , $1959^{\circ}$ e $1955^{\circ}$. Os sinais $+e$ - inaicam existência ou ausência de formas do tipo mórbido em causa. 
Semelhantes quadros clínicos Kleist os isolou desde o início da carreira psiquiátrica, ao desmembrar dos quadros sintomáticos de Wernicke as psicoses acinéticas $\mathrm{e}$ as hipercinéticas ${ }^{9 a}, \mathrm{~b}$, que mais tarde precisou como psicoses da motilidade. Pouco tempo após, em 1911, mostrou ao discutir a "paranóia aguda" de Thomsen a vantagem da orientação patogênica e psicopatológica: os quadros delirantes agudos mantinham maior parentesco com as formas maniacas que com a paranóia. E pacientes dêsse grupo eram como ainda hoje acontece, infelizmente - rotulados como maníaco-depressivos. Cumpria pois identificar o tipo mórbido de causa endógena em que conceitos delirantes expansivos revelavam as tendências latentes ao passo que na desordem circular legítima a configuração clínica se apresenta evidente, reconhecendo-se como constitucional.

Outras eventualidades clínicas, estas mais freqüentemente confundidas com a esquizofrenia, reclamavam a atenção acurada e o senso clínico de Kleist que as caracterizou como estados crepusculares autóctones não desencadeados por convulsões, embora filiáveis ao mesmo fundo genético que a epilepsia. Tais estados de turvação de consciência, de configuração crepuscular estudados sucessivamente em 1923 e em $1926^{\circ \mathrm{h}, \mathrm{i}}$, passavam assim a integrar o grupo das psicoses autóctones degenerativas agrupadas em $1921^{9 \mathrm{c}}$. Endossando sugestōes de Schröder 28a, d, que o secundava em tais investigações, cognominou como degenerativas ao já numeroso grupo de psicoses dessa natureza. Na realidade provinham de dinamismo genético e era devido à influência dos genes que assumiam o feitio clínico semelhante a várias formas constitucionais. Desmembrando das doenças circulares do humor, de Kraepelin, as modalidades correspondentes, das formas delirantes os quadros paranóides, da epilepsia os estados acessuais - isto é, episódicos ou esporádicos - constituiu o grupo das psicoses ciclóides, paranóides e epileptóides ${ }^{9 j}$. Considerava-as ainda marginais porque os psiquiatras não se achavam familiarizados com elas e era quase a regra incluí-las nos grupos clássicos correspondentes. São dessa apresentação as formas clínicas e a comparação que reproduzimos no quadro 4.

Estudos de Gerum 7, Leonhard 18a, b, c, de Mollweide 22, de Neele 23b, de Seige ${ }^{31}$, de Stadler ${ }^{35}$, de Strauss ${ }^{36}$, bem como outros em nosso meio ${ }^{32 e,}{ }^{2}, 33$, $38 a, b$, revelaram a freqüência com que tais formas clinicas incidem em hospitais mesmo de pacientes crônicos. Mais encontradiças ainda se fazem elas em sanatórios para agudos, o que é compreensivel uma vez que a maioria dos quadros clínicos tende para a remissão em breve tempo.

De igual modo que em relação à esquizofrenia, tais quadros foram submetidos intencionalmente também à revisão catamnéstica. $\mathrm{E}$, além disso, foram muitas vêzes registrados nas pesquisas catamnésticas de esquizofrênicos: eram em realidade pacientes de psicose degenerativa nos quais, apesar das cautelas clínicas, o diagnóstico apôsto fôra o de esquizofrenia. Kleist e Driest ${ }^{10}$ dedicam um estudo especial a êste tipo de êrro diagnóstico, que certo figurará entre os mais freqüentes. De fato é fundamental evitá-lo, para que as terapêuticas recentes não tenham falseada a apreciação quanto à eficiência. E é felizmente viável consegui-lo. Mostram-no estudos de von 
FORMAS TIPICAS

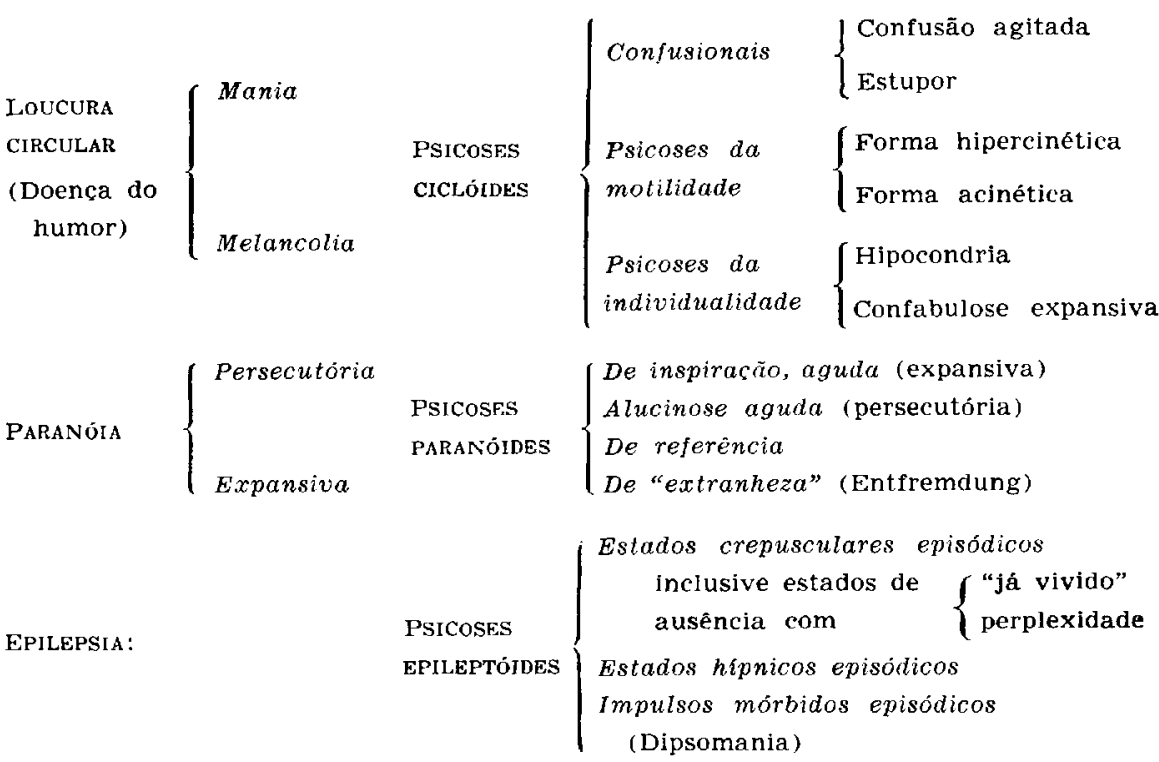

Quadro 4 - Psicoses endógenas diatéticas isoladas por Kleist: confronto com as endógenas constitucionais. Primeira classificaçoo de Kleist ${ }^{3 j}$, traduzida em $1944{ }^{32 h}$

Angyal ${ }^{1}$ em relação à esquizofrenia periódica, de Leonhard ${ }^{18 \mathrm{~m}}$ em sentido geral, de Neele ${ }^{23 a}$ com referência a quadros hipercinéticos, de Schröder ${ }^{28}$ quanto à psicose maníaco-depressiva e à esquizofrenia, de Silveira ao estudar terapêuticas de choque ${ }^{32 c}, \mathrm{~d}, \mathrm{t}$ e ao discutir a orientação das classificações psiquiátricas ${ }^{32 i, j}$, de Speckmann em referência aos estados crepusculares episódicos ${ }^{34}$.

\section{DINAMISMO PATOGÊNICO NAS PSICOSES DEGENERATIVAS}

A intensa verificação dos quadros degenerativos ante a catamnese levou Kleist e colaboradores a alterar a posição e parcialmente a descrição das formas consideradas no quadro 4. Algumas formas, como a alucinose aguda persecutória e a hipocondria, sofreram remanejamento. Após a descrição da psicose ansioso-extática de inspiração, por Leonhard ${ }^{18 e}$, o fato de Neele não encontrar a alucinose persecutória no material catamnéstico fêz com que se cancelasse a rubrica alucinose e fôsse ela substituida pelo delírio ansioso-extático. Em nosso material clinico, entretanto $32 \mathrm{e}, \mathrm{g}, \mathrm{h}, 33$, tal forma ocorre com satisfatória freqüência e de modo assaz característico para que 
a conservemos na classificação, apondo-lhe, porém, a designação ansioso-extática que é de fato pertinente. A hipocondria, que antes se considerava fase oposta à confabulose expansiva, passou a ser conhecida como dupla fase autônoma - agitação hipoconđriaca e depressão hipocondriaca.

A semelhança clínica para com as formas endógenas correspondentes o que lhes atesta o parentesco genético embora evocado por dinamismo diferente - é assinalada pela designação geral de cada grupo, como se vê no quadro 4. Há, porém, duas analogias a considerar: o comportamento genético das formas simples ou monofásicas em relação ao das formas bifásicas é perfeitamente comparável ao modo de se comportarem as esquizofrenias simples em cotejo com as formas combinadas e assistemáticas. Em ambos os têrmos de comparação cresce a carga genética à medida que a forma clínica se atenua. Outra analogia é que os quadros degenerativos de decurso por fases se comparam em têrmos gerais às formas esquizofrênicas sistemáticas, do mesmo modo que as episódicas têm analogia com as formas assistemáticas da esquizofrenia.

Ademais, para acentuar a analogia, pode distinguir-se em cada ciclo das psicoses degenerativas o predominio - patogenético, bem entendido - de um dos três setores da personalidade: afetivo, conativo ou intelectual. $\overline{\mathbf{E}} \mathbf{o}$ que fazemos no quadro 5 , em que tais similitudes patogênicas se apresentam mais claras.

Como o característico fundamental, tanto das psicoses degenerativas que evolvem por surtos como das que decorrem por fases é a tendência latente, acreditamos poder denominá-las em conjunto diatéticas, dado que é êsse também o sentido clássico atribuido à noção de diátese.

A semelhança fenomenológica entre ambos os grupos, encarando agora a esfera fundamentalmente atingida em cada caso e não o dinamismo patogênico apenas, é o que, a nosso ver, ocasiona os diagnósticos de esquizofrenia para os pacientes de psicoses diatéticas. O quadro 6 pretende acentuar êsse aspecto, que julgamos deve imprescindivelmente estar presente ao psiquiatra prático.

\section{CONFRONTO PATOGENICO}

As formas esquizofrênicas cujo traço fundamental é dado pelo desmantêlo afetivo - as da hebefrenia — nāo oferecem variedades assistemáticas. Algumas porém são mais características e mais uniformes pelo decurso e pelo quadro clínico: as do par pueril e depressivo. Note-se que em ambos os casos é o sistema preposto à afetividade que está predominantemente atingido. Na forma apática os distúrbios se manifestam através do sistema conativo e, na autista, mediante o intelectual: em ambos os casos é o profundo transtôrno do interêsse afetivo o que anula a iniciativa respectivamente para agir e para contactuar mentalmente com o mundo exterior. Para compreender o porque das formas clínicas não basta reconhecer simplesmente qual o sentido global - afetivo, psicomotor ou intelectual - que 
preside a exteriorização clínica em causa, segundo o conteúdo do quadro 3. Este último permite, ao contrário, assinalar que ocorrem formas combinadas de esquizofrenias, o que o quadro 6 não comporta.

Quadros simples, mono- \begin{tabular}{c|c|c} 
Decurso por fases \\
fásicos
\end{tabular} \mid $\begin{gathered}\text { Decurso Por SURTOS } \\
\text { Quadros episódicos } \\
\text { fásicos }\end{gathered}$

\begin{abstract}
Agitação hipocondriaca Depressão hipocondriaca De referência, ansiosa De estranheza, perplexa
\end{abstract}

|

Patogênese conativa predominante

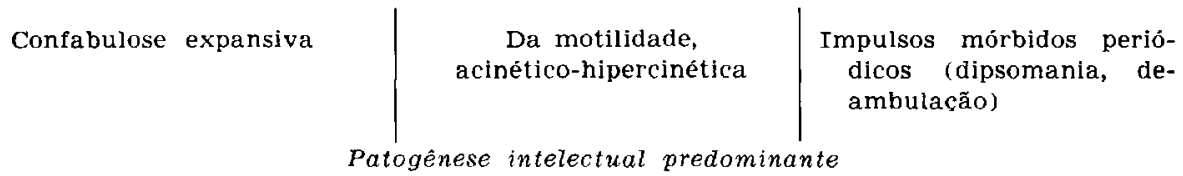
De inspiração, extática

togenese intelectual predominante

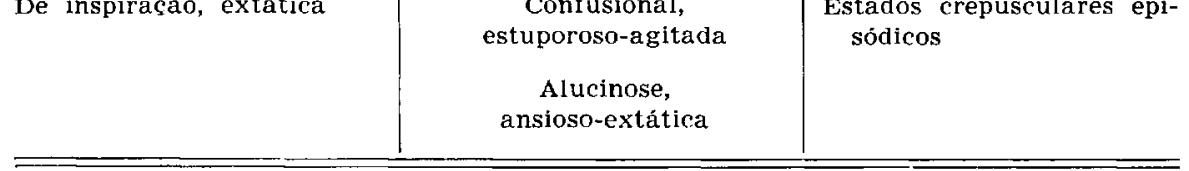

Quadro 5 - Dinamismo patogênico dominante nas várias psicoses endógenas diatéticas. Resumo baseado nas revisões de $1947^{9 p}$ e de $1959^{9 \tau}$.

Já nas psicoses degenerativas marcadas pelo comprometimento da esfera afetiva as interrelações são mais complexas. Comparáveis à hebefrenia pueril e à depressiva ocorrem a agitação e a depressão hipocondriacas. Os sintomas expansão e depressão, bem como o predomínio de sensaçōes corporais em ambos os tipos de psicose, induzem muita vez ao êrro diagnóstico, quase sempre no sentido de considerar esquizofrênico ao paciente de psicose diatética. Psicopatológicamente, porém, não é difícil a distinção, de vez que na hebefrenia as queixas somáticas se revestem de cunho de irrealidade $\mathrm{e}$ na euforia ou na depressão transparece o fenômeno da desagregação. Mais comum, pelo tema prevalente de distúrbios somáticos, é a confusão da hipocondria com a somatopsicose e a autopsicose, progressivas, formas que se alinham entre as paranóides delirantes no quadro 3 , mas cujo fundo afetivo é evidenciado pela situação no quadro 6 , entre os distúrbios do sistema da afetividade. Justamente êste entrelaçamento de sistemas dentro de esferas distintas é que caracteriza as formas diatéticas isoladas por Kleist. Com as modalidades apática e autista da hebefrenia são comparáveis -- fenomenològicamente mas não à luz da patogênese — as psicoses da motilidade em 
fase acinética e a confusão mental estuporosa. Em ambos êstes tipos mórbidos a participação da iniciativa, para agir e para falar, representa o traço patogênico comum. Entretanto o conteúdo psicopatológico - reconhecível quando o estímulo do examinador vence a sideração dos dinamismos conativos - exprime concordância com o estado de humor e não a falência do interêsse afetivo como é êste o caso na hebefrenia.

Traduzem dinamismo primàriamente ligado à esfera da conação as formas diatéticas epileptóides (quadro 5) e as catatônicas (quadro 6). No primeiro grupo, os impulsos mórbidos periódicos representam o quadro mais caracteristico da falência das fôrças conativas de contenção ou de inibição. Mesmo aqui, os dois tipos mórbidos que foram descritos divergem quanto ao dinamismo afetivo que ocasiona o transtôrno da ação explicita: nos impulsos mórbidos da dipsomania são os estimulos vegetativos, profundos e hieràrquicamente inferiores, que se acham em causa; nos da deambulaçāo, ou poriomania, prevalece a liberação da vida de relação, sob a forma de hiperatividade há maior analogia com a hipocondria, principalmente pelo alcance dade há maior analogia com a hipocondria, principalmente com o alcance disfórico e pela autodepreciação que se exprimem bem pela "Verstimmung" da psicopatologia alemã; na segunda os transtornos são mais próximos do estado crepuscular e da confusão agitada, com os quais se confundem no consenso do psiquiatra menos avisado. Vemos assim que mesmo na faixa mais expressiva das alterações conativas de tipo diatético intervêm acentuadamente os dinamismos afetivos e intelectuais. Êstes últimos predominam mais nitidamente no estado crepuscular episódico, no qual, entretanto, a esfera conativa assume o papel fundamental: do mesmo passo que há queda da consciência, pela absorção extrema do dinamismo conativo, surge a agitação como fenômeno de libertação e em geral os efeitos agressivos no acesso crepuscular denunciam a predomināncia dos impulsos destrutivos. Já no episódio hípnico os distúrbios afetivos, também em nivel instintivo, acarretam quebra violenta da vigilia com retração completa para com os estimulos ambientes: interiorização intelectual rápida, sopor e sono paroxistico.

Aos distúrbios conativos que acabamos de referir não se superpōem de modo completo os da catatonia que a êles correspondem nos quadros 3 e 6 . Realmente a troca de diagnóstico dos impulsos mórbidos periódicos e dos estados crepusculares se fazem mais com a excitação maníaca, do mesmo modo que os estados hípnicos não muito acentuados se confundem com a hebefrenia depressiva $\mathrm{e}$ com a confusão mental estuporosa. Todavia não é raro que os estados hípnicos frustos sejam tomados por catatonia negativista e que os estados crepusculares sejam incluídos na catatonia loquaz ou na categoria da esquizofrenia confusional. Isto acontece principalmente em relação à forma assistemática da esquizofrenia confusional por surtos (quadro 3), na qual a marca afetiva é dada pela periodicidade do quadro e pela quebra no nexo ideativo e no contacto intelectual com o ambiente. No campo das formas catatônicas, quadros psicomotores ou conativos, as variedades sistemáticas se dividem em três grupos, segundo o quadro 6: a 


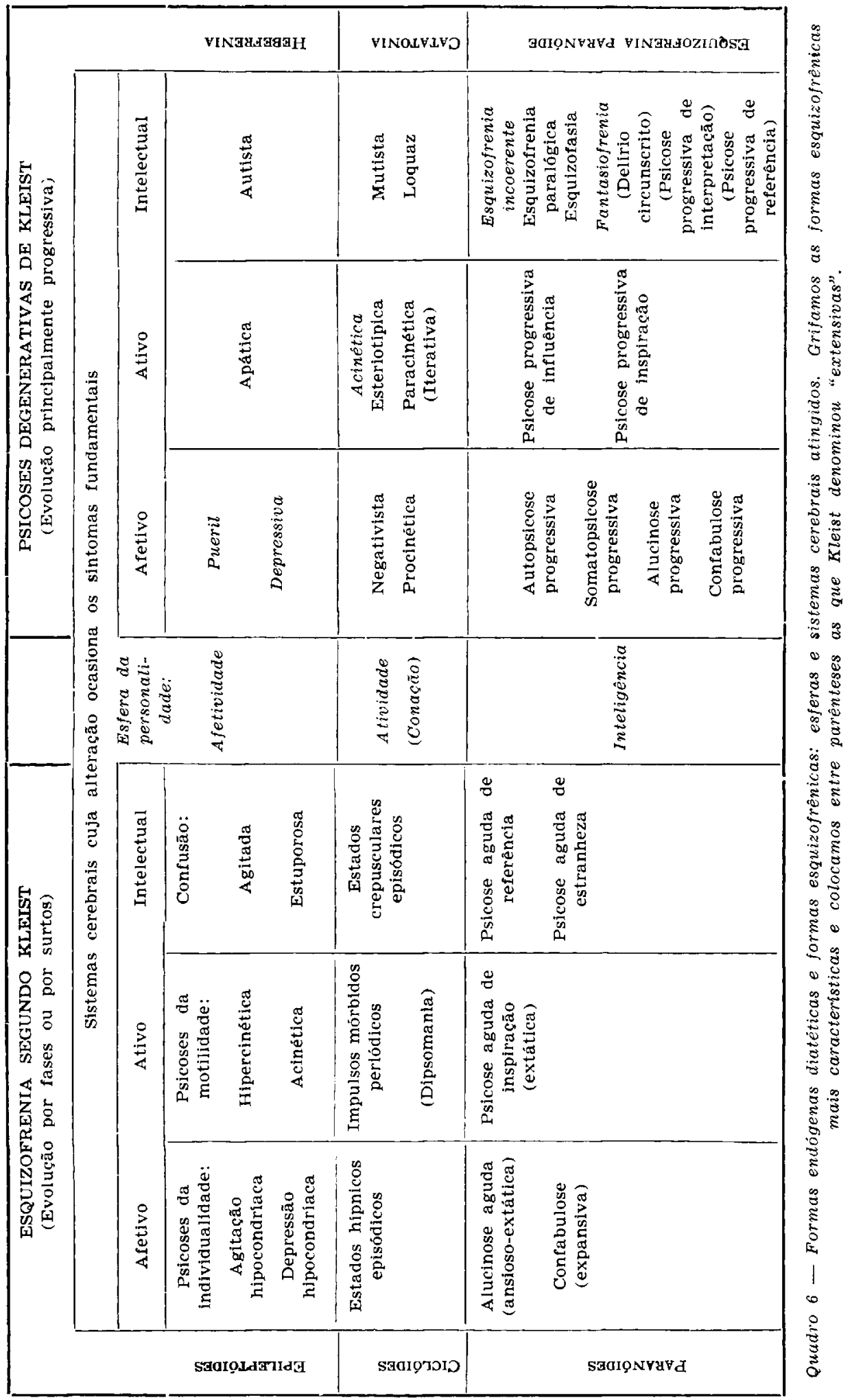


dupla negativista e procinética, que reflete o dinamismo afetivo primário, o grupo em que há falência, desvio ou repetição da atividade explicita isto é, as formas acinética, paracinética e esteriotípica - e o par intelectual, mutista e loquaz. As duas primeiras formas traduzem, respectivamente, o oposicionismo sob forma primitiva de negação e ao contrário a subordinação excessiva, subserviente, ao estímulo externo: o doente aqui obedece imediatamente e como em eco, a todo estímulo que o atinja, seja na esfera motora, seja no plano intelectual, pelo que Kleist designara a forma como proséctica, nome que modificou para procinética por sugestão acertada de Leonhard. Estas mesmas tendências opostas para o retraimento ou para a acessibilidade exagerada caracterizam no setor intelectual as variedades mutista e loquaz.

O predominio da inibição e da perseveração é evidente na catatonia acinética, o que atinge em plano profundo inclusive o sentido da musculação, donde o fenômeno da "flexibilidade cérea"; ao passo que há exagero de iniciativa, concomitante à incapacidade de refreamento, na forma paracinética; e equivalência entre ambas estas funções conativas na forma esteriotípica. Tais variedades, como no caso da hebefrenia, podem associar-se como resultado da fusão de sistemas cerebrais no processo mórbido. E aqui já aparecem formas assistemáticas: o fenômeno da iteração se agrava com dinamismos profundos relativos à regência patológica dos núcleos diencefálicos no caso da forma iterativa; e o processo se estende marcadamente ao sistema afetivo - em plano de atividade cíclica básica - no caso da forma iterativo-esteriotipica por surtos. Tais formas assistemáticas estabelecem paralelo com as modalidades diatéticas epileptóides, em que vários sistemas psiquicos se equivalem como substrato dos distúrbios, dentro da esfera da conação.

A participação predominante da esfera iı telectual se reflete nas formas diatéticas paranóides (quadro 5) e nas esquizofrenias de tipos paranóide e confusional (quadro 3). O quadro 6 ressalta que para cada forma esquizofrênica paranóide existe uma forma diatética correspondente. A diferença fundamental, pelo aspecto patogênico, é que nas formas progressivas o sistema em causa é atingido por deficiência biológica originária, irreparável, embora a decadência resultante possa ocorrer de modo extremamente lento. Em ambos os grupos, a alucinose se caracteriza pelo falseamento das imagens sensoriais no território de todos os sistemas exteroceptivos. Já na somatopsicose e na autopsicose são os sistemas sensoriais proprioceptivo e interoceptivo, respectivamente, a fonte dos distúrbios básicos. A seu turno, essas alterações sistemáticas pressupõem desvios afetivos, respectivamente, em nivel mais profundo - instintivo - e relativamente superficial, para o contacto com o meio ambiente. O resultado psicopatológico, em qualquer dos dois grandes grupos clínicos, é a desordem da noção de si próprio, personalidade somática, ou da noção subjetiva de identidade. A psicose de inspiração e a de influência — também em qualquer dos grupos - decorrem da contribuição afetiva e dos estímulos conativos, nessa ordem. Embora ambos os quadros sejam ligados à interpretação - portanto intelectuais 
quanto ao conteúdo psicológico - na primeira eventualidade é o dinamismo instintivo, de base sobretudo afetiva e impregnada de carga emocional, o que está em causa; na outra eventualidade é do dinamismo conativo, geralmente sob forma de automatismo mental, que se trata. Por sua vez a confabulose tem como traço dominante o aspecto intelectual da construtividade, que depende, no plano lógico normal, do estímulo afetivo mais diferenciado. Na confabulose - também nas duas modalidades clínicas se exteriorizam a euforia, repassada de êxtase, ou a ansiedade (quadro 5), ou ainda a perda de noção do real, com falseamento da própria identidade (quadro 3). Finalmente no domínio da expressão dos conteúdos psicológicos encontramos alteraçōes comparáveis nos estados crepusculares - entre as formas diatéticas do quadro 5 - e esquizofrênicos, como no quadro 3 . Na esquizofrenia confusional, como alteração intrínseca dos sistemas correspondentes, os distúrbios são mais marcantes e melhor caracterizados: às formas paralógica e incoerente correspondem transtornos na atividade mental de elaboração, extrínseca naquele caso, intrínseca neste; na fantasiofrenia é a produtividade exagerada, sem a devida retificação das concepções em face da realidade exterior, o que está em jôgo; e, finalmente, na esquizofasia é a atividade discursiva, de comunicação, que revela a alteração fundamental. Existe analogia acentuada para com as formas diatéticas de predominio intelectual - principalmente a de inspiração, a confusional e os estados crepusculares - embora estas se filiem, no plano clínico, aos grupos paranóide, ciclóide e epileptóide, respectivamente (quadro 4).

Ėstes comentários têm a intenção de acentuar a necessidade de nortear-se o diagnóstico em Psiquiatria pelos ensinamentos da patogenia e não pela descrição fenomenológica. Mesmo que não fôsse pelas conseqüências de ordem prática - para os conhecimentos médicos e principalmente para os doentes - o prisma da psicopatologia e da patogênese imprimiria maior segurança ao raciocínio clínico e mais amplitude às deduções que ao psiquiatra sugere o material humano ao qual se vota cotidianamente.

\section{RESUMO}

Impõe-se o diagnóstico diferencial das formas esquizofrênicas entre si e para com numerosas doenças hoje confundidas com elas. Entre estas sobreleva considerar as psicoses endógenas benignas, de Kleist, as quais têm sido em geral diagnosticadas como esquizofrenia.

Kleist distingue na esquizofrenia 25 formas autônomas, para o que se baseia em rigoroso critério ao mesmo tempo patogênico, psicopatológico, heredológico-evolutivo. Tais divisões foram confirmadas por amplas revisões catamnésticas em base genética após cinco anos de decurso, no mínimo. Tanto na fase inicial (quadro 1) quanto na presente (quadro 3) a sistemática se fundamenta na concepção de sistemas cerebrais. $\dot{E}$ a participação predominante dos diferentes sistemas, no âmbito das várias esferas psíquicas, o que imprime o colorido clínico principal aos quadros mórbidos. Estes constituem assim (quadro 2) formas sistemáticas e assistemáticas. 
As psicoses endógenas benignas, descritas por Kleist (quadros 4 e 5) obedecem a dinamismos patogênicos precisos e também envolvem sistemas cerebrais distintos, que são os que lhes imprimem o característico clínico. Os fatôres fundamentais são as tendências genéticas, não manifestas como nas psicoses endógenas constitucionais, mas latentes. Por isso Kleist as cognominava de início degenerativas, atípicas, e marginais às endógenas comuns; acreditamos poder chamá-las diatéticas, como designação geral, uma vez que o conceito de diátese corresponde a tendências genéticas latentes. Algumas formas têm decurso cíclico ou por fases; outras ocorrem como surtos esporádicos ou episódicos. No quadro 6 procuramos distribuir as formas diatéticas e as formas esquizofrênicas segundo as esferas e os sistemas cerebrais envolvidos em comum. Cremos que é o dinamismo patogênico, em ambos os casos, o que leva à confusão diagnóstica, quando o psiquiatra não o toma em devida conta.

\section{SUMMARY}

Schizophrenias and degeneration psychoses, after Kleist. Differential pathogenesis and psychopathology

It is most relevant to make the differential diagnosis in the several forms of schizophrenia with one another and especially against a number of psychoses. Among the latter ones are Kleist's benign endogenous psychoses, almost always labeled schizophrenias.

On the basis of a close criterion at a time pathogenic, pathopsychologic and heredobiologic-evolutional, Kleist describes 25 forms of schizophrenia. These have been ascertained by large and meticulous follow-up, human genetic-minded, after at least 5 years of course. Such set of patterns, initially as well as in the revised form (Tables 1 and 3 ), is based on the conception of brain systems. It is the specifical working of these systems, within any psychic sphere, that stamps on the clinical variety its distinctive traits. Thus, as shown on Table 2, the schizophrenias may be either systematic or unsystematic in type.

The endogenous benign psychoses described by Kleist (Tables 4 and 5) also recognize precise pathogenic dynamisms regarding cerebral systems, which explain the clinical patterns. Their underlying causes are genetic trends, not overt as in the constitutional psychoses, but in latency. This is why Kleist called them degeneration psychoses, atypical endogenous or marginal regards the common ones. Since the term diathesis refers to such latent traits, we assume they may also be called diathetic endogenous psychoses. Some clinical forms follow a cyclic course, other ones occur as isolated attacks. Table 6 shows side by side the diathetic and the schizophrenic forms, according to the spheres and psychic systems envolved. We feel that it is the pathogenic dynamism in both instances what misleads the diagnosis when the psychiatrist does not bear it in mind. 


\section{REFERENCIAS}

1. ANGYAL, L. von - Beiträge zur periodischen Schizophrenie und den schizophrenen Dämmerzuständen. Allg. Z. f. Psychiat., 102:185, 1934.

2. EDELMANN, R. - Untersuchungen zur Unterteilung der Schlzophrenien. Allg. Z. f. Psychiat., 120:24, 1942.

3. FAUST, C. - Die progressive Halluzinose, Z. f. Neurol., 172:308, 1941.

4. FAUST, E. - Zur Frage der latenten Schizophrenien in den Sippen manifest Schizophrener. Monatschr. f. Psychiat., 125:65, 1953.

5. FISH, F. J. - a) The classification of schizophrenia. The views of Kleist and his co-workers. J. Ment. Sci., 103:443, 1957; b) A clinical investigation of chronic schizophrenia. J. Ment. Sci., 104:34, 1958; c) Leonhard's classification of Schizophrenias. J. Ment. Sci., 104:943, 1958.

6. FUNFGELD, E. - a) Anatomisches zur Auffassung der Schizophrenie als psychische Systemerkrankung. Arch. f. Psychiat., 71:2, 1924; b) Die Motilitätspsychosen und Verwirrtheiten. Karger, Berlim, 1936; c) Bemerkungen zur Histopathologie der Schizophrenie. z. Neurol., 158:232, 1937.

7. GERUM, K. - Beitrag zur Frage der Erbbiologie der genuinen Epilepsie, der epileptoiden Erkrankungen und der epileptoiden Psychopathien. Z. f. Neurol., 115:319, 1928.

8. HERz, E. - Zur Differentialdiagnose zwischen Verwirrtheiten, Motilitätspsychosen und Katatonie. Schw. Arch. f. Psychiat., 23, 1928.

9. KLEIST, K. - a) Untersuchungen zur Kenntnis der psychomotorischen Bewegungstörungen bei Geisteskranken. Klinkhardt, Leipzig, 1908; b) Weitere Untersuchungen an Geisteskranken mit psychomotorischen Störungen. Brandstetter, Leipzig, 1909; c) Die Streitfrage der akuten Paranoia. Ein Beitrag zur Kritik des manisch-depressiven Irreseins. Z. 1. Neurol., 5:366, 1911; d) Uuber paranoide Erkrankungen. Allg. Z. f. Psychiat., 71:764, 1914; e) Bericht über endogene Verblödungen. Allg. Z. f. Psychiat., 75:242, 1919; f) Autocthone Degenerationspsychosen. Z. f. Neurol., 69:1, 1921, $g$ ) Die Auffassung der Schizophrenien als psychische Systemerkrankungen (Heredodegenerationen). Klin. Wschr., 21:962, 1923; $h$ ) Episodlsche Dämmerzustände. Zbl. Neurol., 33:83, 1923; i) Episodische Dämmerzustände. Georg Thieme, LeipzIg, 1926; $j$ ) Uber zykloide, paranoide und epileptoide Psychosen und über die Frage der Degenerationspsychosen. Schw. Arch. f. Psychiat., 23:3, 1928; k) Zur hirnpathologischen Auffassung der schizophrenen Grundstörungen. Schw. Arch. f. Psychiat., $26: 99,1930 ; l)$ Störungen des Denkens und ihre himpathologischen Grundlagen. In ROGGENBAU: Gegenwartsprobleme usw. Springer, Berlim, 1939; $m$ ) Bericht ủber die Gehirnpathologie in ihrer Bedeutung für Neurologie und Psychiatrie. Z. 1. Neurol., 158:159, 334, 1937; $n$ ) Die Katatonien. Nervenarzt, 16:1, 1943; o) Die paranolden Schizophrenien. Nervenarzt, 18:481, 544, 1947; p) Fortschritte der Psychiatrie. Kramer, Frankfurt am Main, 1947; q) Las esquizofrenias paranoides. Actas luso-esp. Neurol. y Psiquiat., 10:2, 1951; $r$ ) Die Gliederung der neuropsychischen Erkrankungen. Monatschr. f. Psychiat., $125: 526,1953$.

10. KLEIST, K.; DRIEST, W. - Die Katatonien auf Grund katamnestischer Untersuchungen: Die als Katatonien verkannten Degenerationspsychosen, Psychosen der Schwachsinnigen und symptomatischen Psychosen. Z. Neurol., 157:479, 1937.

11. KLEIST, K.; HERZ, E. - a) Psychomotorische Akinese, Hyperkinesen und Dyskinesen bei Katatonie. Med. Filmvoche 3, Stilke, Berlim, 1925-1926; b) Die Motilitătspsychosen. Med. und Film 18, 1926.

12. KLEIST, K.; LEONHARD, K.; FAUST, E. - Die Hebephrenien auf Grund von katamnestischen Untersuchungen. Arch. Psychiat., u. Z. Neurol., 185:733, 1950 und 186:1, 1951. 
13. KLEIST, K.; LEONHARD, K.; PITTRICH, H. - Katatonie. Inst. Film. u. Bild Wissensch, Unterricht 447, Göttingen, 1952.

14. KLEIST, K.; LEONHARD, K.; SCHWAB, H. - Die Katatonien auf Grund katamnestischer Untersuchungen: Formen und Verläufe der eigentlichen Katatonie. Z. Neurol., 168:535, 1940.

15. KLEIST, K.; SCHWAB, H. - Die verworrenen Schizophrenien auf Grund katamnestischer Untersuchungen: Die denkverwirrten Schizophrenien. Arch. Psychiat. U. Z. Neurol., 184:28, 1950.

16. KLEIST, K.; WISSMANN, D. - Zur Psychopathologie der unerlaubten Entfernung usw. Allg. Z. f. Psychiat., 76:30, 1920.

17. KNAUF, H. W. - Die Formen der Schizophrenien von Kleist und Leonhard nachgeprüft in einer Anstalt für chronisch Kranke. $z$. menschl. Vererb. $u$. Konstit. lehre, 29:695, 1950.

18. LEONHARD, K. - a) Episodische Dämmerzustände (Kleist) mit gleichartiger Vererbung. Monatschr. f. Psychiat., 81:226, 1931; b) Atypische endogene Psychosen im Lichte der Famllienforschung. Z. f. Neurol., 149:520, 1934; c) Zur Frage der episodischen Dämmerzustände. Z. f. Neurol., 154:242, 1936; d) Die defektschizophrenen Krankheitsbilder. Georg Thieme, Leipzig, 1936; e) Das ängstlich-ekstatische Syndrom aus innerer Ursache (Angst-Eingebungspsychose) und äusserer Ursache (Symptomatische Psychosen). Allg. Z. 1. Psychiat., 110: 101, 1939; f) Zur Untertellung und Erbbiologie der Schizophrenien. Allg. Z. f. Psychiat., 120:1, 1942; $g$ ) Kombiniert-systematische und periodische Katatonien. Allg. Z. f. Psychiat., 121:1, 1942; $h$ ) Erbbiologie der Katatonien. Allg. Z. f. Psychiat., 122:39, 1943; i) Die paranoiden und verworrenen Schizophrenien typischer und kombiniert-systematischer Art. Allg. Z. f. Psychiat., 122:194, 1943; j) Die periodischen und phantastisch fortschreitenden paranoiden Schizophrenien mit ihrem Sippenbild. Allg. Z. f. Psychiat,, 123:9, 1944; $k$ ) Erbbiologie der paranoiden und verworrenen Formen von Schizophrenie. Allg. Z. f. Psychiat., 123:177, 1944; l) Die hebephrenen Krankheitsformen und inr Erbbild. Psychiat.-neurol. Wschr., 47:23, 1945; $m$ ) Grundlagen der Psychiatrie. Enke, Stuttgart, 1948; n) Einige kombiniert-systematische Schizophrenien. Allg. z. f. Psychiat., 124:409, 1949; o) Eine Sippe affektvoller Paraphrenie mit gehäuftern Erkrankungen aus Verwandten-Ehen (Zugleich ein Beitrag zur Frage der Paranoia). Arch. f. Psychjat. u. Z. Neurol., 184:291, 1950; $p$ ) Formen und Veriäufe der Schizophrenien. Monatschr. f. Psychiat., 124:169, 1952.

19. MEYER, G.; LEONHARD, K.; KLEIST, K. - Die paranoiden Schizophrenien auf Grund katamnestischer Untersuchungen: Die paranoide Demenz (Progressive Auto- und Somatopsychosen). Z. f. Neurol., 177:114, 1944.

20. MINkOWSkI, E. - La Schizophrénie. Payot Ed., Paris, 1927.

21. MIRA Y LOPEZ, E. - Manual de Psiquiatría, ed. 1, Salvat, Barcelona, 1935.

22. MOLLWEIDE, H. - Neue somatische Ergebnisse bei einer Kranken mit episodischen Dämmerzustände. Nervenarzt, 19:49, 1948.

23. NEELE, E. - a) Krampftherapie und Differentialdiagnose der bedrohlichen Hyperkinese. $z$. Neurol., 178:2, 1944; b) Die phasischen Psychosen nach ihrem Erscheinungs- und Erbbild. Barth, Leipzig, 1949.

24. NEELE, E.; KLEIST, K. - Die progressive Beziehungspsychosen. z. f. Neurol., $175: 4,1942$.

25. SCHNEIDER, A. - Studien über Sprachstörungen bei Schizophrenen (Schizophasien). Z. f. Nelrol., 108:491, 1927.

26. SCHNEIDER, F. W. - Untersuchungen an Schizophrenen eines Reservelazarettes des zweiten Weltkriegs (Nachprüfung der Formen von Kleist und Leonhard). Schw. Arch. 1. Psychiat., 72, 1955.

27. SCHNEIDER, K. - Die Diagnose der Schizophrenie. Georg Thieme, Leipzig, 1936. 
28. SCHRODER, P. - a) Die Splelbreite der Symptome beim manisch-depressiven Irresein und bei Degenerationspsychosen. Karger, Berlim, 1920; b) Degeneratives Irresein und Degenerationspsychosen. Z. f. Neurol., 60:119, 1920; c) Degenerationspsychosen und Dementia praecox. Arch. f. Psychiat., 66:1, 1922; d) Uber Degenerationspsychosen (Metabolische Erkrankungen). Z. f. Neurol., 105: $539,1926$.

29. SCHULTE-von der STEIN, C. - Nachprüfung der Kleist-Leonhardschen Schizophrenieformen in den Frauenabteilungen einer Heil- und Pflegeanstalt. Arch. 1. Psychiat. u. z. Neurol., 193:303, 1955.

30. SCHWAB, H. - a) Die Katatonie auf Grund katamnestischer Untersuchungen: Die Erblichkeit der eigentlichen Katatonie. Z. f. Neurol., 163:441, 1938; b) Die phantastisch-paranoiden Erkrankungen. Z. f. Neurol., 173:38, 1941; c) Die verworrenen Schizophrenien auf Grund katamnestischer Untersuchungen: Die Schizophasien. Arch. f. Psychiat. u. Z. Neurol., 182:333, 1949; d) Zur Frage der echten zirkulär-schizophrenen "Mischpsychose". Allg. 2. 1. Psychiat., 125:101, 1949.

31. SEIGE, D. - Klinisch-katamnestische Untersuchungen an epileptoiden Störungen. Arch. f. Psychiat. u. Z. Neurol., 193:347, 1955.

32. SILVEIRA, A. - - a) Lesōes casuais e lesōes sistemáticas do cérebro nas doencas mentais. Arq. Assist. Psicopatas de São Paulo, 2:191, 1937; b) Contribuiçāo para o tratamento convulsivante nos esquizofrēnicos. Tentativa de explicação para os resultados. Arq. Assist. Psicopatas de São Paulo, 2:391, 1937; c) Behandlung Schizophrener mittels Insulin- oder Konvulsionsshocks? Klinischer Beitrag für die Auswahl der Kranken. Z. f. Neurol., 166:604, 1937; d) Einige Fehlerquellen die sich bei den modernen Schizophreniebehandlungen vermeiden lassen. Allg. Z. Psychiat., 114:125, 1940; e) Psicoses degenerativas. Estados crepusculares episódicos (Kleist). Cinco observaçôes clinicas pessoais. Rev. Paulista Med., 18:134, 1941; f) O método de Meduna em esquizofrēnicos crónicos. Tese de Docência. Fac. Med. de Sāo Paulo, 1941; g) Psicoses degenerativas (Kleist). Considerações sôbre cinco novos casos. Arq. Assist. Psicopatas de São Paulo, 9: $254,1944 ; h)$ A classificaçăo nacional das doenças mentais. Arq. Assist. Psicopatas de São Paulo, 9:73, 1944; i) Génétique et Eugénie. Discussion of Dr. Kallmann's Report. Congr. Mondial Psychiatrie, Paris, 1950. Eugen. News, $36: 27,1951 ; j$ ) Human genetics as an approach to the classification of mental diseases. Arq. Neuro-Psiquiat., 10:41, 1952.

33. SIlveira, A.; Robortella, M.; VIzzoTTO, S.; MElSOHN, I.; SALles, o. B. - Psicopatologia nas psicoses degenerativas de Kleist. V Congr. Brasil. de Psiquiatria, Neurol. e Med. Legal, São Paulo, 1948.

34. SPECKMANN, K. - Beitrag zur Differentialdiagnose und Erbbegutachtung der episodischen Dämmerzustände (Kleist). Allg. Z. f. Psychiat., 110:69, 1939.

35. STADLER, H. - zur Frage der Beziehungen zwischen periodischen und episodischen Dämmer- und Schlafzuständen. Monatschr. f. Psychiat., 98:317, 1938.

36. STRAUSS, H. - Zur Kasuistik und Auffassung der Narkolepsie. Monatschr. f. Psychiat., 61:265, 1926.

37. TOMCHINSKY, R. B. - Esquizofrenias confusas. Arq. Assist. Psicopatas de São Paulo, 21:143, 1955.

38. vizzotto, s. - a) Heredologia nas psicoses degenerativas de Kleist. Rev. Paulista Med., 39:390, 1951; b) Classificação das psicoses degenerativas (Kleist). Rev. Paulista Med., 44:432, 1954.

39. VizzotTo, S.; MELSOHN, I. - Esquizofasia. Arq. Neuro-Psiquiat., 17:208 (junho) 1959 . 